\title{
Risks inherent in fetal gene therapy
}

Sir - We wish to express our opposition to W. French Anderson's proposed gene therapy experiments on fetuses, which are likely to result in genetic changes in fetal germline cells (Nature 395, 420; 1998).

We are not opposed to fetal gene therapy in principle. However, the UK Gene Therapy Advisory Committee should be congratulated for ruling out direct injection of viral vectors into fetuses on safety and ethical grounds. We believe that Anderson's proposals constitute the first step towards intentional human germline genetic engineering, which will mainly be used for purposes of 'enhancement'. It is vital that the widely accepted prohibition on human germline genetic engineering be maintained.

The proposed experiments, intended to treat severe combined immune deficiency (SCID), are scientifically premature given current lack of success with somatic gene therapy. Furthermore, there are alternative therapies for SCID, such as neonatal bone marrow transplantation, especially where a newborn child is known to be at risk.

Although heritable changes will be, formally speaking, an unintentional consequence of the experiments, they are predicted and likely, and could therefore be considered as deliberate. Anderson is on record as supporting germline engineering for certain purposes, and has said that he intends to "force the debate" on human germline genetic engineering. These facts suggest that the proposed experiments should be treated as intentional human germline genetic engineering.

However, there is a danger that the experiments will be approved within US regulatory guidelines, because intentional germline changes are not the stated purpose of the experiment.

The prohibition on human germline genetic engineering, established in law in many countries, is well founded on social and ethical grounds. There are very few examples where existing alternatives, such as gamete donation and preimplantation genetic diagnosis, would not provide the opportunity for families affected by genetic disease to have genetically related children. There are also the traditional options of adoption and non-parenthood. We believe that, once its use became established for medical purposes, it would be impossible to prevent the use of germline engineering for purposes of 'enhancement'.

We urge the US Recombinant DNA Advisory Committee and regulators in other countries to follow the lead of the United Kingdom, and reject Anderson's proposals. David King ${ }^{\star}$, Tom Shakespeare $\dagger$, Richard Nicholson $\ddagger$, Angus Clarke $\$$, Sheila McLeang ${ }^{*}$ GenEthics News, PO Box 6313,

London N16 0DY, UK

$\dagger$ Department of Sociology, University of Leeds, Woodhouse Lane, Leeds LS2 9JT, UK $\ddagger$ Bulletin of Medical Ethics, 8 Rose Cottage, 22-24 Highbury Grove, London N5 2EA, UK $\$$ Institute of Medical Genetics, University Hospital of Wales, Heath Park, CardiffCF4 4FW, UK

School of Law, University of Glasgow,

Glasgow G12 8QQ, UK

Anderson replies - I welcome the chance to respond to the thoughtful letter of King et al. On one issue we absolutely agree: the use of germline genetic engineering for purposes of "enhancement" would be a calamity for society. But concern about potential future misuse should not be allowed to prevent the legitimate development of a technology that can save lives and relieve suffering.

King et al. and their colleagues at the US Council for Responsible Genetics (CRG) believe that the danger is so great that no attempt at fetal gene therapy should be allowed that could result in any germline gene transfer. I disagree. A new technology that can save lives should not be rejected because of a theoretical risk. As a paediatrician I have spent my life attempting to reduce the suffering and death of children. Fetal gene therapy offers a powerful technology that could correct genetic diseases which now produce irreversible damage before birth, so avoiding the need for alternative techniques such as gamete donation, embryo selection, abortion, adoption or non-parenthood.

King et al. are incorrect in stating that fetal gene therapy is "likely to result in genetic changes in fetal germline cells". Our proposal is to treat the second-trimester fetus (not the embryo), by which time all organ systems have formed. There is no evidence that gene transfer could take place into the primary germ cells even if it were desired. All the published data indicate that germline gene transfer is highly unlikely, or may not even be possible, using present techniques (see, for example, refs 1 and 2). So "heritable changes" are not "deliberate", and it is incorrect to state that "the proposed experiments should be treated as intentional human germline genetic engineering".

It is misleading for King et al. to state that other countries should "follow the lead of the United Kingdom, and reject Anderson's proposals". Our proposals have never been submitted to any UK body. We did not ask the US Recombinant DNA Advisory Committee for approval: we requested that a discussion of these issues should begin. The committee commended us for our actions.

The real issue is how to reap the benefits of fetal gene therapy while avoiding misuse. I believe the best defence for society is an educated public. Therefore I applaud King et al. and the CRG for their commendable efforts to raise public awareness of these issues. We have presented our proposals several years before we will be ready to carry out fetal gene therapy, to allow the public to evaluate our efforts at every stage. If we cannot reduce the risk of germline gene transfer to a minimal level, we will not proceed with our proposed studies.

\section{W. French Anderson}

Gene Therapy Laboratories, University of Southern California School of Medicine, Los Angeles, California 90033, USA

1. Ye, X. et al. Hum. Gene Ther. 9, 2135-2142 (1998). 2. Porada, C. D. et al. Hum. Gene Ther. 9, 1571-1585 (1998).

\section{Visible viruses and}

\section{geodesic domes}

Sir - Martin Kemp's" article "Visible viruses" incorrectly credits Brenner and Horne with introducing negative staining and Wildy and Watson with recognizing the parallels between virus structure and Buckminster Fuller's geodesic domes. His discussion of capsid design omits key points. H. E. Huxley's ${ }^{2}$ high-resolution study of tobacco mosaic virus made the 'outline' of the virus visible, with a clear hole down the middle, saying: "This 'outlining' technique ... is so simple and gives excellent contrast and resolution".

Caspar and Klug's ${ }^{3}$ comparison of the geodesic domes of Buckminster Fuller to the viral capsid design is discussed by Marks ${ }^{4}$ : "Dr A. Klug and Dr J. T. Finck [ sic] ... wrote to Fuller enclosing published reports of their discovery of the icosa-geodesic structuring of the polio virus. In conversations with Fuller ... they intimated that all spherical viruses comprise geodesic arrangements of proteins in systems similar to Fuller's frequency modulated geodesic structures."

Finally, Kemp asks whether capsid design is constrained by the physical principles underlying macromolecular assemblies, by the principles governing the encoding of design in the genome, or both. The question revolves around function and inheritability — how does the virus genome protect itself in transit between cells?

A simple solution was proposed by Crick and Watson ${ }^{5}$, who considered how to fit the 
information for a large container into a small genome. They argued that the repeated use of a single protein to form a symmetric viral capsid could require as little as one gene, making efficient use of genetic information. Today, asymmetrical designs, like those of the cytoskeleton, capture our imagination. Their routes to self-assembly, unlike the pathway described by Lewis Carroll, do not keep "one principle object in view - to preserve its symmetrical shape".

\section{David J. DeRosier}

(Director)

W. M. Keck Institute of Cellular Visualization,

Brandeis University, Waltham,

Massachusetts 02454, USA

1. Kemp, M. Nature 396, 123 (1998)

2. Huxley, H. E. Proceedings of the Stockholm Conference on Electron Microscopy 260-261 (Stockholm, 1956).

3. Caspar, D \& Klug, A. Cold Spring Harb. Symp. Quant. Biol. XXVII, 1-24 (1962)

4. Marks, R. W. The Dymaxion World of Buckminster Fuller (Reinhold, New York, 1960).

5. Crick, F. H. C. \& Watson, J. Nature 177, 473-475 (1956).

\section{Spanish researchers} defeated by the system

Sir - It is with the utmost satisfaction that I read the articles on Spanish universities Nature 396, 709 , 712; 1998). So far, the press, with a few exceptions which now include Nature, have simply echoed the encouraging words of the present and previous Spanish governments. Though many alleged 'reforms' of the last 15 years may look quite sensible, insiders can see that successive governments have promised much and delivered nothing. They claim to devote more funds to research, hoping the figures won't look too embarrassing when Spain's scientific budget is compared with those of other EU members every year.

It is true that, as the science budget has increased, so has the number of publications. It is also true that several research groups are among the best in the world in their fields. What the Government fails to mention is how many publications are by Spanish scientists working abroad, and how many are the result of international collaborations. The top groups'

achievements are more due to the devotion of their members than to any government policy. The Government's zealousness in allocating more research funding has never been followed by any interest in ensuring that these funds (often from the EU rather than the Spanish budget) were properly used. There are no inspections, no yield assessments, no questions asked.

Against this background, vast sums of money have been invested in the creation of dozens of ridiculously small and unnecessary universities over the past decade. Hundreds of positions have been created and filled - most, if not all, by local applicants with hardly enough experience to defend a master's thesis. These people are now being promoted to permanent professorships, while much more qualified candidates are humiliated and rejected on the most extraordinary grounds. In return for making these appointments, the university rectors and heads of departments ensure their own right to do exactly as they please, if anything at all.

The case of Dr Férriz, described in your articles, would not surprise any Spanish scientist. In fact, what would be surprising is to learn that at least one Spanish university has not yet been sued. I took the University of Seville to court in 1994, for very similar reasons to those of Dr Férriz. The outcome of the litigation, which I expect any time within the present geological era, is as unpredictable as next week's lottery results, given that the Spanish legal system is as anachronistic and bureaucratic as the one that rules the universities, and judges only rarely consider information from independent researchers.

It results in a system which is essentially unfair and leaves everybody defenceless. I personally will not attempt to return to Spain until the Government, for the first time in history, seriously decides to implement a rational science policy. Francisco Rodríguez-Quiñones

School of Biological Sciences,

University of Birmingham, Edgbaston B15 2TT, UK

\section{Can teaching ethics make people ethical?}

Sir - In a leading article you claim that "extreme misconduct tends to occur most frequently" in biomedical research (Nature $395,727 ; 1998)$. You fail to cite data to substantiate the claim that extreme misconduct in biomedical sciences is more frequent than in other sciences, but it is obvious that it is vastly more frequent than is acceptable. It is also embarrassingly obvious that more ethics is probably taught in medical faculties than in any other scientific discipline. It is hard to find a medical school in the developed world without at least some formal medical ethics education. But I doubt if any mathematics or physics departments offer courses in 'mathematical ethics' or 'physical ethics'.

Those of us who teach medical ethics must therefore ask ourselves the hard question whether we are really teaching what we ought to teach, and whether 'ethical people' can really be produced by academic instruction. Classes on ethics of genetic engineering, cloning, brain death and when the embryo becomes a person can be exciting and intellectually stimulating but they don't necessarily make physicians, nurses and biomedical researchers more honest.

\section{Frank J. Leavitt}

Medical Ethics Centre, Faculty of Health Sciences, Ben Gurion University of the Negev,

Beer Sheva, Israel

email:yeruham@bgumail.bgu.ac.il

\section{Glaciation: the snowball}

\section{theory still holds water}

Sir-D. M. Williams et al. ${ }^{1}$ propose a

mechanism $^{2}$ whereby an initial high

obliquity for the Earth could have rapidly changed to its present low value of $\sim 23.5^{\circ}$ near the end of the Proterozoic eon. Following G. Williams ${ }^{3}$, they note that the mean annual insolation would have been lower at the Equator than at the poles if the Proterozoic obliquity exceeded $54^{\circ}$. They infer that low-latitude glaciation observed near the beginning and end of the Proterozoic could be explained without the need for an ice-covered 'snowball' Earth ${ }^{4,5}$.

However, neither Williams et al. ${ }^{1}$ nor the accompanying News and Views article ${ }^{6}$ discuss the implications of high obliquity for glaciation per se. The basic requirement for glaciation is a net accumulation of winter snow after summer melting. High obliquity enhances seasonality ${ }^{3,7}$, creating very cold winters with reduced snowfall and very hot summers with maximal melting.

The recognition that glaciation is favoured by cool summers, not cold winters, is the crucial difference between the Milankovitch theory and the much earlier Croll theory of orbital forcing ${ }^{8}$. High obliquity has the greatest effect on seasonality at the poles, but insolation during the warm seasons at the equator is equally high irrespective of obliquity.

Whatever merit it has for the early Earth ${ }^{1}$, high obliquity seems insufficient as an explanation for low-latitude glaciation ${ }^{7}$ and glaciating the poles as a means of reducing a high obliquity ${ }^{1}$ is highly improbable.

Paul F. Hoffman, Adam C. Maloof Department of Earth \& Planetary Sciences, Harvard University, Cambridge,

Massachusetts 02138, USA

1. Williams, D. M., Kasting, J. F. \& Frakes, L. A. Nature 396, 453-455 (1998).

2. Bills, B. G. Geophys. Res. Lett. 21, 177-180 (1994).

3. Williams, G. E. Earth-Sci. Rev. 34, 1-45 (1993).

4. Kirschvink, J. L. in The Proterozoic Biosphere (eds Schopf, J. W. \& Klein, C.) 51-52 (Cambridge Univ. Press, New York, 1992).

5. Hoffman, P.F., Kaufman, A. J., Halverson, G. P. \& Schrag, D. P. Science 281, 1342-1346 (1998).

6. Bills, B. G. Nature 396, 405-406 (1998)

7. Hunt, B. G. J. Meteorol. Soc. Jpn. 60, 309-318 (1982).

8. Imbrie, J. \& Imbrie, K. P. Ice Ages (Harvard Univ. Press, Cambridge, 1979). 